\title{
Casos clínicos de Medicina de Família
}

\author{
Case reports on Family Pratice \\ Casos clínicos de Medicina Familiar \\ José Agostinho Santos ${ }^{1 *}$
}

\section{Caro Editor,}

Como leitor, regozijo-me perante o espaço da RBMFC concedido aos relatos de casos clínicos, contrariando a tendência existente em outras revistas médicas de não os considerar matéria de publicação. Esta tendência deve-se, provavelmente, ao fato de que artigos de casos clínicos não são tradicionalmente alvos fortes de citação por outros autores ${ }^{1}$. Porém, são estes artigos que alertam o médico, de forma notória, para a diversidade dos quadros clínicos e que exploram o potencial que os casos guardam enquanto forças motrizes para introspeção clínica, ponderação das nossas atitudes ou divulgação de estratégias que nos encorajam para uma melhor qualidade nos cuidados prestados.

O impacto de um relato de caso poderá ser desproporcionalmente grande perante o seu real poder estatístico. Se uma série de casos tem um valor diminuto no suporte científico para as decisóes clínicas, tampouco um caso clínico teria consistência para tal. Os estudos de grande peso para as nossas decisóes são os ensaios clínicos de boa qualidade ${ }^{2}$. Não deixa de ser curioso, portanto, que o relato de caso clínico capte a nossa atenção de forma tão sedutora. Poder-se-ia elaborar uma explicação para tal: o caso clínico não pretende ter impacto científico nas nossas decisóes, mas sim constituir um alerta para o comportamento clínico que tantas vezes antecede as decisóes ${ }^{3}$.

A literatura revela que alguns guidelines têm impacto abaixo do esperado na prática do médico comum $^{4}$. Elaboradas por peritos, é surpreendente como entre o conhecimento (awareness) destas diretrizes até à sua aplicação (adherence), seja percorrido um longo caminho que passe também pela concordância (agreement) e adoção (adoption), pelo que o seu impacto perde-se no meio desse trajeto ${ }^{4}$. Várias razóes poderão justificar esta relativa inoperância das diretrizes mas uma delas é a desvinculação notória ao ambiente diário do clínico comum, patente nos alvos estabelecidos ${ }^{4}$. Isto poderá ser altamente negativo, pois afasta o médico da evidência que constituirá o melhor alicerce científico no exercício da medicina e que é "preconizada" pelas sociedades científicas. Quanto ao caso clínico, este aspecto está ausente. O colega que o apresenta tem "carne, pele e osso" e transmite raciocínios e dúvidas que o clínico comum facilmente identifica. Esta identificação entre pares será a ignição para o despertar de um

\footnotetext{
${ }_{1}^{1}$ Unidade de Saúde Familiar Lagoa, Senhora da Hora, Portugal. zeagostinho@hotmail.com 
processo de reflexão que passe por questôes como: - "Qual seria o meu papel naquele caso? Seria capaz de uma abordagem semelhante?". Ao contrário das guidelines normativas de tom frio, o caso clínico rapidamente acende as brasas pelo calor das dúvidas partilhadas entre colegas.

Neste âmbito, os casos clínicos em Medicina de Família e Comunidade (MFC) tem potencial para gerar fogueiras. Sendo uma especialidade com competências próprias, como a modelação holística ou abordagem abrangente ${ }^{5}$, as estratégias a partilhar na resolução de dilemas são inúmeras e rapidamente discutidas pelos que se identificam com o ambiente tão peculiar da consulta generalista do MFC. É importante que o colega que apresenta um caso clínico evidencie o papel do médico de família e comunidade. Caso contrário, não há muito a ser acrescentado às diretrizes teóricas e assertivas, sem componente humano visível, mas com um rigor inquestionável.

Em congressos, é da minha observaçáo que denoto a desconexáo que surge na plateia quando há uma abordagem centrada na doença, subestimando o valor das competências próprias da MFC. O médico de família não está centrado apenas na doença e é este aspecto que o diferencia na abordagem do paciente. Ele centra também, e talvez primordialmente, no adoecer vivenciado pela pessoa. Este é, na realidade, o aspecto mais gerador de necessidade de partilha de estratégias. A abordagem da doença não exige necessariamente um especialista em MFC, mas a abordagem do adoecer exige, certamente, um clínico que melhor entenda a pessoa sob o ponto de vista biopsicossocial5.

Os processos de formaçáo de médicos residentes em MFC deveriam evidenciar o impacto da MFC enquanto especialidade única na abordagem da pessoa. Dois conceitos são essenciais para uma melhor percepção deste impacto: doença e adoecimento. Uma boa estruturação mental destes conceitos fortaleceria a qualidade do trabalho do MFC.

Muito obrigado à RBMFC por contribuir tão sublimemente para estas linhas de formação!

\section{Referências}

1. Kidd M. The relevance of case reports in Family Medicine. Rev Port Med Geral Fam 2012; 28: 11-2.

2. Ebell MH, Sikew J, Weiss BD, Woolf SH, Susman J, Ewingman B, et al. Strength of Recommendation Taxonomy (SORT): a patient-centered approach to grading evidence in the medical literature. Am Fam Physician 2004 Feb 1; 69(3): 548-56. Pmid:14971837.

3. Melo M. Elaboração de relatos de casos. Rev Port Clin Geral 2001; 17: 487-92

4. Heneghan C, Perera R, Mant D, Glasziou P. Hypertension guideline recommendations in general practice: awareness, agreement, adoption, and adherence. Br J Gen Pract 2007; 57(545): 948-52. PMid:18252069 PMCid:2084133. http://dx.doi.org/10.3399/096016407782604965

5. Wonca Europa. A definição europeia de Medicina Geral de Familiar. Wonca Europa; 2002. p. 6-14. 